\title{
Distinction of Sialyl Anomers on ESI- and FAB-MS/MS: Stereo-Specific Fragmentations
}

\author{
Yoko Ohashi, ${ }^{a}$ Masayuki Kubota, ${ }^{\text {b }}$ Hiroshi Hatase, ${ }^{\text {a }}$ Mitsuhiro Nakamura, ${ }^{\text {a }}$ \\ Takashi Hirano, ${ }^{a}$ Haruki Niwa, ${ }^{\text {a }}$ and Yoshitaka Nagai ${ }^{\mathrm{c}}$ \\ a Department of Applied Physics and Chemistry, The University of Electro-Communications, Tokyo, Japan \\ b ThermoFisher Scientific, Kanagawa, Japan \\ ${ }^{\mathrm{c}}$ Frontier Research System, RIKEN, Saitama, Japan
}

An anomeric pair of the lysoglyceroganglioside 1-O-octadecyl-3-O-(N-acetyl)neuraminyl-snglycerol sodium salt was studied to see if sialic anomers were distinguishable by mass spectra. It was evident that, in the electrospray ionization and fast-atom bombardment product-ion spectra: (1) in the positive $\mathrm{MS}^{2}$ product-ion spectrum, the $\beta$ - anomer showed an unexpected aglycone-side sodiated sodium alkoxide ion, which was absent for the $\alpha$-anomer; (2) in both polarities the $\beta$-anomer showed dehydration much more easily than the $\alpha$-anomer; and (3) in the negative $\mathrm{MS}^{2}$ product-ion spectrum, the $\beta$-anomer also readily showed decarboxylation. Our hypothesis is that, although several easily interconvertible conformations may be allowed, the one having the large aglycone in the equatorial orientation affects the collision-induced dissociation fragmentations. (J Am Soc Mass Spectrom 2009, 20, 394-397) (c) 2009 Published by Elsevier Inc. on behalf of American Society for Mass Spectrometry

$\mathrm{T}$ The necessity for distinguishing sugar anomers has led to many new methodologies on simple sugars like mono- or disaccharides [1-4]. We report here the differences on the electrospray ionization (ESI) $\mathrm{MS}^{2}$ and $\mathrm{MS}^{3}$ product-ion spectra of lysoglyceroganglioside anomers and seek to elucidate the differences based on stereochemical considerations. Such differences also apply to fast-atom bombardment mass spectrometry (FABMS).

Sialic acid is one of the most important sugars for mammals. In normal life events, its conjugates, particularly gangliosides, are deeply involved in fertilization, development, cell-cell recognition, cell differentiation, and even in the programmed cell death. Gangliosides are also heavily related to cancer and other diseases. Studies of sialyl compounds are rapidly expanding these days in particular to meet the imminent threat of avian influenza infection, in which sialic acid may play a critical role.

To study the structure-activity relationships, detailed structural information has to be clarified. Nuclear magnetic resonance (NMR) has served that purpose for years. However, soft ionization mass spectrometry often provides structural information parallel to or even exceeding what can be provided by NMR.

Indeed, positional isomers and even linkage isomers in the same branching sugar unit are distinguishable by using mass spectrometry [5-9]. Among all, the most

Address reprint requests to Dr. Yoko Ohashi, Brain Science Institute, RIKEN, 2-1 Hirosawa, Wako, Saitama 351-0198, Japan. E-mail: ohashi@brain.riken.jp Present address: Brain Science Institute, RIKEN, 2-1 Hirosawa, Wako, Saitama 351-0198, Japan. difficult isomer analysis is the distinction of stereoisomers. We previously reported the epimer distinction on $\mathrm{N}$-acetyllactosamine-6,6'-disulfate [10]. Here we report mass spectrometry of an anomeric pair of lysoglycerotype ganglioside. We selected product-ion mass spectrometry applying both ESI- and FAB-ionization methods, and we found that they showed similar tendencies with respect to their major fragmentation. However, ESI modes with high mass resolving power definitely produced more differences in the fragmentations and consumed less sample. We show here that mass spectrometric differences between anomers are not peculiar, but can be reasonably explained through stereochemical rationalizations.

Yu and Ledeen reported in 1969, using an anomeric pair of methylketosides of $\mathrm{N}$-acetylneuraminic acid that, on dehydration with dicyclohexylcarbodiimide in hot pyridine, the neuraminidase-resistant isomer gave two lactones, whereas the enzyme-susceptible anomer did not [11]. They assumed that a flipover of the neuraminyl ring would cause the carboxyl group at $\mathrm{C} 1$ to approach the $\mathrm{C} 4$-hydroxyl group, resulting in lactone formation for the $\beta$-anomer.

This idea of $Y u$ and Ledeen may explain our present experimental result of ready dehydration of the $\beta$ anomer in both positive- and negative-ion mass spectrometry. The thermal energy required for the rotation among conformers was preliminarily estimated by PM3 semi-empirical molecular orbital calculations of the $\beta$-anomer as an anion and was found to be much less than $100 \mathrm{kcal} / \mathrm{mol}$, which would be available as a result of ionization and collision activation. The two chair
(C) 2009 Published by Elsevier Inc. on behalf of American Society for Mass Spectrometry. $1044-0305 / 09 / \$ 32.00$

doi:10.1016/j.jasms.2008.10.020
Published online November 6, 2008 Received May 1, 2007 Revised October 16, 2008 Accepted October 23, 2008 
forms and intermediate conformers are probably interconverting.

\section{Experimental}

\section{Samples}

An anomeric pair of 1-O-octadecyl-3-O-(N-acetyl) neuraminyl-sn-glycerol sodium salt ( $\mathrm{M}^{\prime} \mathrm{W}$ 657.4, where $\mathrm{M}^{\prime}$ stands for the sodium salt) was synthesized and resolved by HPLC and anomeric configurations were assigned by NMR. The samples were used as $\mathrm{CH}_{3} \mathrm{OH} /$ $\mathrm{H}_{2} \mathrm{O}(1: 1)$ solutions at a concentration of $10 \mathrm{ng} / \mu \mathrm{L}$.

\section{Instrumentation}

For ESI experiments, an LTQ Orbitrap mass spectrometer (ThermoFisher Scientific, Kanagawa, Japan) was used in the accurate mass measurement mode with the spray voltages $5 \mathrm{kV}$ for the positive-ion mode and $4 \mathrm{kV}$ for the negative-ion mode. Capillary temperature was $250{ }^{\circ} \mathrm{C}$. The $\mathrm{MS}^{\mathrm{n}}$ fragmentation was induced by $\mathrm{He}$, optimized by the normalized collision energy method based on the MRFA (methionyl-arginyl-phenylalanylalanine) fragmentation efficiency. ${ }^{1}$ Precursor isolation width was $2 \mu$. Samples were introduced to the capillary by infusion at a rate of $5 \mu \mathrm{L} / \mathrm{min}$. The accurate

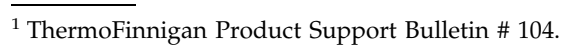

mass measurement was performed in the ESI-MS ${ }^{2}$ mode with a mass resolving power of 100,000.

\section{Results and Discussion}

Positive-ion ESI-MS of the anomeric pair of 1-O-octadecyl3-O-(N-acetyl)neuraminyl-sn-glycerol sodium salt showed the $\left[\mathrm{M}^{\prime}+\mathrm{Na}\right]^{+}$at $m / z 680.5$ with $\left[\mathrm{M}^{\prime}+\mathrm{H}\right]^{+}$at $m / z 658.4$ and little difference between the isomers. However, the product-ion spectra of the two anomeric $\left[\mathrm{M}^{\prime}+\mathrm{Na}^{+}\right.$at $\mathrm{m} / \mathrm{z} 680.5$ showed clear differences from each other. Whereas the $\alpha$-anomer underwent dehydration to give a modest ion at $m / z 662.3$, the $\beta$-anomer not only presented this ion at extraordinary high abundance but also the next dehydration ion at $m / z 644.4$ in a considerable abundance. The sodiated $B^{2}$ [12] at $m / z 336.2$, corresponding to the dehydrated sialate, appeared as expected, but with evidently higher abundance for the $\alpha$-anomer than for the $\beta$-anomer. A peculiar ion at $m / z 389.4$ was prominent for the $\beta$-anomer, but almost invisible for the $\alpha$-anomer (Figure 1). Indeed, the relative abundance of $m / z 389$ to 336 was different between the anomers.

It is generally considered that sugar conformations prefer to have functional groups in the equatorial orientation, that is, C1-conformation for hexopyranose

\footnotetext{
${ }^{2}$ Here $B$ designates the fragment ion containing the nonreducing end sugar unit on the nonreducing end side of the glycosidic oxygen as indicated by Domon and Costello [12].
}
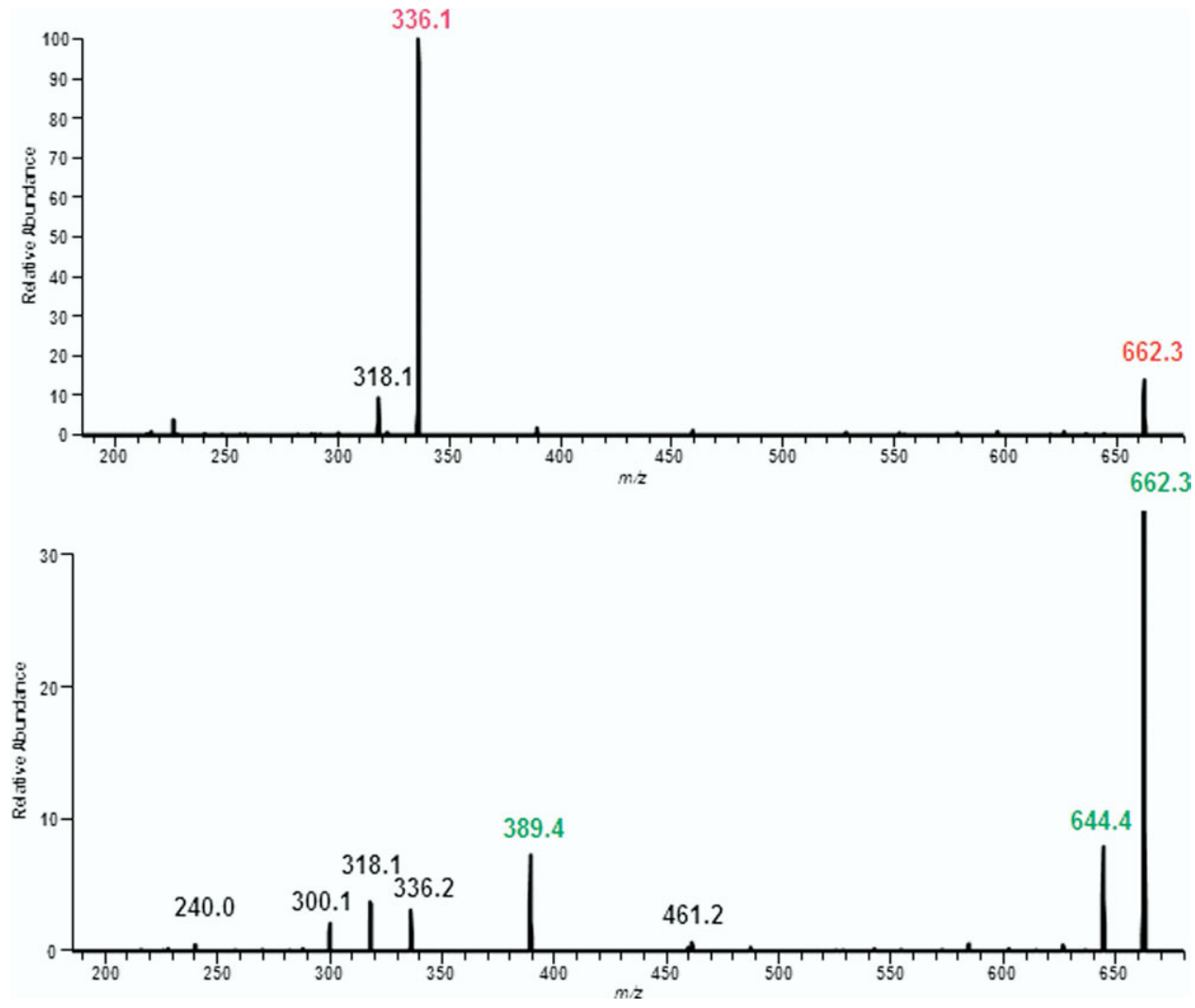

Figure 1. (+) ESI- MS ${ }^{2}$ product-ion spectra of $\left[\mathrm{M}^{\prime}+\mathrm{Na}\right]^{+}$at $m / z$ 680.5: for $\alpha$-anomer (upper), and for $\beta$-anomer (lower) of 1-O-octadecyl-3-O-( $\mathrm{N}$-acetyl)neuraminyl-sn-glycerol sodium salt. 

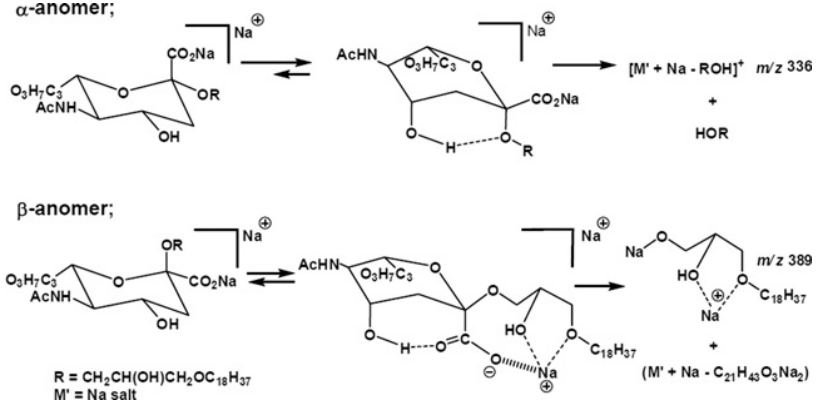

Scheme 1

and $2 \mathrm{C}$-conformation ${ }^{3}$ for the neuraminyl ring, minimizing steric strains. However, we assume that pyranose rings may take a boat or twist-boat form under the internal energy conditions of the ESI product-ion mass spectrometry. The $\beta$-anomer protrudes a conspicuously large aglycone group in the axial orientation if the normal 2C-conformation is taken. Contrarily, this largest group of the $\beta$-anomer extends outward if a boat or twist-boat conformation is adopted, victimizing the more stable orientation (e) for $4^{\prime}-\mathrm{OH}^{4}{ }^{4} 5^{\prime}-\mathrm{NHCOCH}_{3}$, and $6^{\prime}$-glyceryl groups. This assumption came from our

${ }^{3}$ Here, $2 \mathrm{C}$ represents the pyranose-ring conformation equivalent to ${ }^{1} \mathrm{C}_{4}$ if an ordinary hexose numbering is applied, but it would be ${ }^{2} \mathrm{C}_{5}$ if the neuraminyl ring numbering is applied.

${ }^{4}$ Numberings here are 1, 2, 3, and so forth for the aglycone sn-glycerol and $1^{\prime}, 2^{\prime}, 3^{\prime}$, and so forth for the neuraminyl ring. observation of the product-ion at $\mathrm{m} / \mathrm{z} 389$ for the $\beta$-anomer, corresponding to the sodiated $Y_{0}$ $\left[\mathrm{NaO}-\mathrm{CH}_{2}-\mathrm{CH}(\mathrm{OH})-\mathrm{CH}_{2}-\mathrm{OC}_{18} \mathrm{H}_{37}+\mathrm{Na}\right]^{+}$. The elemental composition $\mathrm{C}_{21} \mathrm{H}_{43} \mathrm{O}_{3} \mathrm{Na}_{2}$ was confirmed by an accurate mass measurement: $\mathrm{m} / \mathrm{z} 389.3013$.

We assume that some part of the $\beta$-anomer is in the boat or twist-boat conformation as illustrated in Scheme 1. Here, $\mathrm{Na}^{+}$attaches to the neutral aglycone moiety, leaving the carboxyl group free to approach the $4^{\prime}-\mathrm{OH}$ group, whereas the second sodium ion coordinates the glyceryl-3-ether as well as the 2-hydroxyl oxygen.

In the case of the $\alpha$-anomer, the group that may easily approach the $4^{\prime}-\mathrm{OH}$ is the ketosidic oxygen rather than the carboxyl, if a similar boat or twist-boat conformation is taken. Then, the aglycone alcohol leaves as a neutral and the sialyl residue becomes sodiated to give a product-ion $B$ at $m / z 336$ as shown in Scheme 1 .

Such representation, with the distance between carboxylate and the $4^{\prime}-\mathrm{OH}$ being closer for the $\beta$-anomer than for the $\alpha$-anomer, also explains why the production spectrum of $\left[\mathrm{M}^{\prime}+\mathrm{Na}\right]^{+}$of the $\beta$-anomer showed an ion of $\left[\mathrm{M}^{\prime}+\mathrm{Na}-\mathrm{H}_{2} \mathrm{O}\right]^{+}$at $m / z$ 662.3, in much higher intensity than the $\alpha$-anomer, reminding us of a lactone formation suggested by Ledeen and Yu's chemistry.

In the negative-ion $\mathrm{MS}^{2}$ product-ion spectra having $\left[\mathrm{M}^{\prime}-\mathrm{Na}\right]^{-}$at $m / z 634.5$ as the precursor-ion, fragment ions in common are an expected $B$ ion at $\mathrm{m} / \mathrm{z} 290.1$, in which the $\alpha$-anomer showed more relative intensity
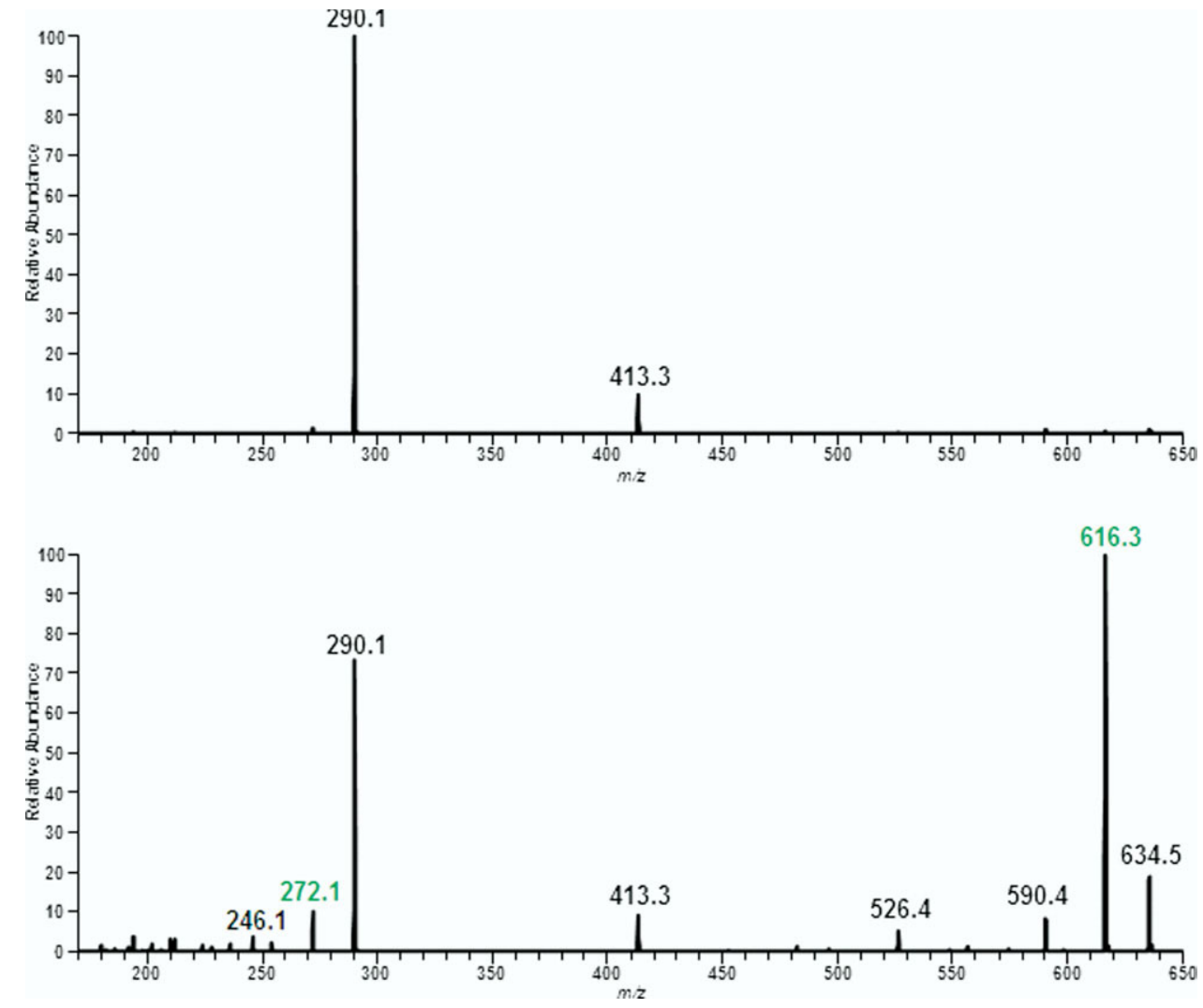

Figure 2. (-) ESI- MS ${ }^{2}$ product-ion spectra having $\left[\mathrm{M}^{\prime}-\mathrm{Na}\right]^{-}$at $m / z 634.5$ as the precursor-ion: for $\alpha$-anomer (upper) and for $\beta$-anomer (lower) of 1-O-octadecyl-3-O-( $\mathrm{N}$-acetyl)neuraminyl-sn-glycerol sodium salt. 
than the counter anomer, and another ion at $m / z 413.3$ as shown in Figure 2. Additionally, the $\beta$-anomer showed several extra product-ions, that is, an obvious ion at $\mathrm{m} / \mathrm{z}$ 616.3 as the most abundant product-ion produced by dehydration, another at $m / z$ 590.4, equivalent to [ $\mathrm{M}^{\prime}-$ $\left.\mathrm{Na}-\mathrm{CO}_{2}\right]^{-}$, reflecting the easier decarboxylation of the $e$-orientation; at $\mathrm{m} / \mathrm{z} 526.4$ corresponding to the loss of the C-6'-glyceryl side chain, $\left[\mathrm{M}^{\prime}-\mathrm{Na}-\mathrm{H}_{2} \mathrm{O}-\right.$ $\left.\mathrm{C}_{3} \mathrm{H}_{6} \mathrm{O}_{3}\right]^{-}$; at $m / z 272.1$ for $\left[B-\mathrm{H}_{2} \mathrm{O}\right]^{-}$; and at $m / z 246.1$ for $\left[\mathrm{B}-\mathrm{CO}_{2}\right]^{-}$.

However, the $\mathrm{MS}^{3}$ product-ion spectra, specifying the $B$ ion at $m / z 290.1$ as the $\mathrm{MS}^{2}$ ion of $\left[\mathrm{M}^{\prime}-\mathrm{Na}\right]^{-}$, showed further fragmentation more or less in the same way for the both anomers. It is noteworthy that in this $\mathrm{MS}^{3}$ product-ion spectra, the $\left[\mathrm{M}^{\prime}-\mathrm{Na}\right]^{-}$at $m / z 634.5$ produces a $B$ ion at $m / z$ 290 followed by the ion at $m / z 272$ even for the $\alpha$-anomer, which failed to show this ion at $m / z 272$ as the MS ${ }^{2}$ production of $\left[\mathrm{M}^{\prime}-\mathrm{Na}\right]^{-}$(Figure 2).

Thus, we started to examine the fate of the $\mathrm{MS}^{2}$ product-ion at $m / z 616.3$, which is the most abundant for the $\beta$-anomer but absent for the $\alpha$-anomer. The $\mathrm{MS}^{3}$ product-ion spectrum of the $\beta$-anomer having $\left[\mathrm{M}^{\prime}-\mathrm{Na}\right]^{-}$ at $m / z 634.5$ as the $\mathrm{MS}^{1}$ and $\left[\mathrm{M}^{\prime}-\mathrm{Na}-\mathrm{H}_{2} \mathrm{O}\right]^{-}$at $m / z$ 616.3 as the $\mathrm{MS}^{2}$ ion indicates that in the case of the $\beta$-anomer, the $m / z 272$ ion was additionally produced by means of $\left[\mathrm{M}^{\prime}-\mathrm{Na}-\mathrm{H}_{2} \mathrm{O}\right]^{-}$, bypassing the $B$ ion at $m / z 290$.

Although unrelated to anomer distinctions, a common product-ion of $\left[\mathrm{M}^{\prime}-\mathrm{Na}\right]^{-}$at $m / z 413$ in Figure 2 also caught our attention. The accurate mass of 413.3278 for both the $\alpha$-anomer and the $\beta$-anomer fit the composition $\mathrm{C}_{24} \mathrm{H}_{45} \mathrm{O}_{5}$ (calculated exact mass: 413.32615, confirming the ion to be the $\left.{ }^{0,3} \mathrm{X}\right)$.

\section{Conclusions}

An anomeric pair of 1-O-octadecyl-3-O-( $\mathrm{N}$-acetyl) neuraminyl-sn-glycerol sodium salt gave clearly different ESI and FAB product-ion spectra than its anomer in the positive- and negative-ion modes. The differences can be explained by the facile bending of the neuraminyl ring among conformers when collision energy is imparted.

Sialic acid is generally believed to assume the ${ }^{2} C_{5}$ conformation. However, if a twist-boat, boat, or the other chair form is also available, one of the anomeric bonds may approach the C-4' hydroxyl hydrogen. It is important to take into account that sugar rings, even with a large aglycone, may change conformations, driven possibly by excess ionization energy or by collisional activation. In our case, the $\beta$-anomer easily loses water molecule from the precursor-ion, opening an extra fragmentation route in the negative-ion mode.

We are proposing plausible mechanisms to rule out just coincidental differences in anomer mass spectra. We also acknowledge that other research groups have successfully distinguished anomers by mass spectrometry [13-20]. Among them, we are particularly interested in the report by Leavell et al. [1] because they studied conformations of metal complexes of sugars.

\section{Acknowledgments}

The anomeric pair of 1-O-octadecyl-3-O-( $\mathrm{N}$-acetyl)neuraminyl-snglycerol sodium salt was a kind gift from Dr. Yuji Matsuzaki of Tokyo Kasei Co. Ltd., and Dr. Isao Kijima-Suda of Racing Laboratories. We are most grateful to Dr. Shojiro Maki, Dr. Satoshi Kojima of The University of Electro-Communications, and students in the laboratory as well as to Ms. Eiko Wada of The Institute of Medical Science, The University of Tokyo, for their moral support and kind interest.

\section{References}

1. Leavell, M. D.; Gaucher, S. P.; Leary, J. A.; Taraszka, J. A.; Clemmer, D. E. Conformational Studies of Zn-Ligand-Hexose Diastereomers Using Ion Mobility Measurements and Density Functional Theory Calculations. J. Am. Soc. Mass Spectrom. 2002, 13, 284-293.

2. Gabryelski, W.; Froese, K. L. Rapid and Sensitive Differentiation of Anomers, Linkage, and Positional Isomers of Disaccharides Using High-Field Asymmetric Waveform Ion Mobility Spectrometry (FAIMS). J. Am. Soc. Mass Spectrom. 2003, 14, 265-277.

3. Polfer, N. C.; Valle, J. J.; Moore, D. T.; Oomens, J.; Eyler, J. R.; Bendiak, B. Differentiation of Isomers by Wavelength-Tunable Infrared MultiplePhoton Dissociation-Mass Spectrometry: Application to GlucoseContaining Disaccharides. Anal. Chem. 2006, 78, 670-679.

4. Dwivedi, P.; Bendiak, B.; Clowers, B. H.; Hill, H. H., Jr. Rapid Resolution of Carbohydrate Isomers by Electrospray Ionization Ambient Pressure Ion Mobility Spectrometry-Time-of-Flight Mass Spectrometry (ESI-APIMS-TOFMS). J. Am. Soc. Mass Spectrom. 2007, 18, 1163-1175.

5. Ii, T.; Ohashi, Y.; Nagai, Y. Structural Elucidation of Underivatized Gangliosides by Electrospray-Ionization Tandem Mass Spectrometry (ESIMS/MS). Carbohydr. Res. 1995, 273, 27-40.

6. Ii, T.; Ohashi, Y.; Nunomura, S.; Ogawa, T.; Nagai, Y. Fast Atom Bombardment and Electrospray Ionization Tandem Mass Spectrometry of Sulfated Lewis ${ }^{x}$ Trisaccharides. J. Biochem. 1995, 118, 526-533.

7. Ii, T.; Ohashi, Y.; Ogawa, T.; Nagai, Y. Negative-Ion Fast Atom Bombardment and Electrospray Ionization Tandem Mass Spectrometry for Characterization of Sulfated and Sialyl Lewis-Type Glycosphingolipids. Glycoconj. J. 1996, 13, 273-283.

8. Ii, T.; Ohashi, Y.; Ogawa, T.; Nagai, Y. A New Approach to the Characterization of Sulfated and Sialyl Lewis-Type Glycosphingolipids Using Positive-Ion FABMS, ESIMS and CID-MS/MS. J. Mass Spectrom. Soc. Jpn. 1996, 44, 183-195.

9. Ohashi Y.; Ii, T.; Kubota, M.; Nunomura, S.; Niwa, H.; Ohashi, M.; Ogawa, T.; Nagai, Y. FAB CID-MS/MS of In-Source Fragment Ions as a Means to Differentiate Linkage Isomers of Branched Oligosaccharides: $\mathrm{Le}^{\mathrm{a}}$ and $\mathrm{Le}^{\mathrm{x}}$ Type Glycoconjugates. J. Mass Spectrom. Soc. Jpn. 1998, 46, 45-52.

10. Ohashi, Y.; Itoh, Y.; Kubota, M.; Hamada, K.; Ohashi, M.; Hirano, T.; Niwa, H. Analysis of Sugar Epimers Using Mass Spectrometry: $N$-Acetyllactosamine-6,6'-disulfate and the 2'-Epimer. Eur. J. Mass Spectrom. 2004, 10, 269-278.

11. Ledeen, R. W.; Yu, R. K. Chemistry and Analysis of Sialic Acid. In Biological Roles of Sialic Acid, Rosenberg, A.; Schengrund, C.-L., Eds.; Plenum Press: New York, 1976; pp 19-22.

12. Domon, B.; Costello, C. E. A Systematic Nomenclature for Carbohydrate Fragmentations in FAB-MS/MS Spectra of Glycoconjugates. Glycoconj. J. 1988, 5, 397-409.

13. Mendonca, S.; Cole, R. B.; Zhu, J.; Cai, Y.; French, A. D.; Johnson, G. P. Laine, R. A. Incremented Alkyl Derivatives Enhance Collision Induced Glycosidic Bond Cleavage in Mass Spectrometry of Disaccharides. J. Am. Soc. Mass Spectrom. 2003, 14, 63-78.

14. Kameyama, A.; Kikuchi, N.; Nakaya, S.; Ito, H.; Sato, T.; Shikanai, T.; Takahashi, Y.; Takahashi, K.; Narimatsu, H. A Strategy for Identification of Oligosaccharide Structures Using Observational Multistage Mass Spectral Library. Anal. Chem. 2005, 77, 4719-4725.

15. Yamagaki, T. Studies of Post-Source Decay of Carbohydrates and Their Structure Analyses. J. Mass Spectrom. Soc. Jpn. 2004, 52, 72-83.

16. Kurimoto, A.; Daikoku, S.; Mutsuga, S.; Kanie, O. Analysis of EnergyResolved Mass Spectra at MS $^{n}$ in a Pursuit to Characterize Structural Isomers of Oligosaccharides. Anal. Chem. 2006, 78, 3461-3466.

17. Daikoku, S.; Ako, T.; Kurimoto, A.; Kanie, O. Anomeric Information Obtained from a Series of Synthetic Trisaccharides Using Energy Resolved Mass Spectra. J. Mass Spectrom. 2007, 42, 714-723.

18. Costello, E. C.; Contado-Miller, J. M.; Cipollo, J. F. A Glycomics Platform for the Analysis of Permethylated Oligosaccharide Alditols. J. Am. Soc. Mass Spectrom. 2007, 18, 1799-1812.

19. Daikoku, S.; Ako, T.; Kato, R.; Ohtsuka, I.; Kanie, O. Discrimination of 16 Structural Isomers of Fucosyl Galactoside Based on Energy-Resolved Mass Spectrometry. J. Am. Soc. Mass Spectrom. 2007, 18, 1873-1879.

20. Zhu, X.; Sato, T. The Distinction of Underivatized Monosaccharides Using Electrospray Ionization Ion Trap Mass Spectrometry. Rapid Commun. Mass Spectrom. 2007, 21, 191-198. 